\title{
Elemental Mass Size Distribution for Characterization, Quantification and Identification of Trace Nanoparticles in Serum and Environmental Waters
}

\author{
Xiao-xia Zhou, ${ }^{\dagger, \ddagger}$ Jing-fu Liu, ${ }^{*}, \dagger \neq$ and Gui-bin Jiang ${ }^{\dagger, \ddagger}$ \\ ${ }^{\dagger}$ State Key Laboratory of Environmental Chemistry and Ecotoxicology, Research Center for Eco-Environmental Sciences, Chinese \\ Academy of Sciences, P.O. Box 2871, Beijing 100085, China \\ ${ }^{\ddagger}$ University of Chinese Academy of Sciences, Beijing 100049, China
}

\section{Supporting Information}

\begin{abstract}
Accurate characterization, quantification, and identification of nanoparticles (NPs) are essential to fully understand the environmental processes and effects of NPs. Herein, the elemental mass size distribution (EMSD), which measures particle size, mass, and composition, is proposed for the direct size characterization, mass quantification, and composition identification of trace NPs in complex matrixes. A one-step method for the rapid measurement of EMSDs in $8 \mathrm{~min}$ was developed through the online coupling of size-exclusion chromatography (SEC) with inductively coupled plasma mass spectrometry (ICP-MS). The

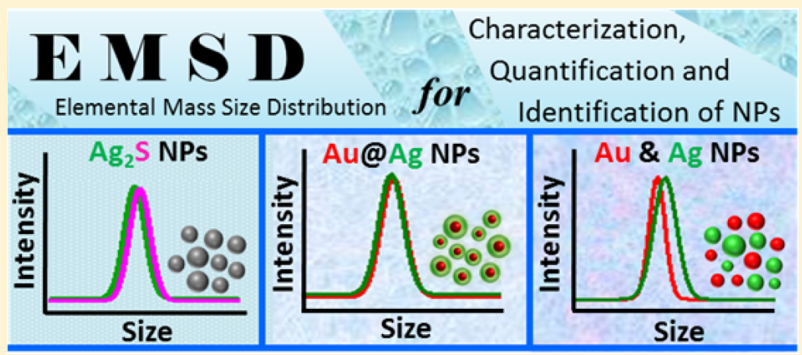
use of a mobile phase with a relatively high ionic strength (a mixture of $2 \%$ FL-70 and $2 \mathrm{mM} \mathrm{Na}_{2} \mathrm{~S}_{2} \mathrm{O}_{3}$ ) ensured the complete elution of different-sized NPs from the column and, therefore, a size-independent response. After application of a correction for instrumental broadening by a method developed in this study, the size distribution of NPs by EMSD determination agreed closely with that obtained from transmission electron microscopy (TEM) analysis. Compared with TEM, EMSD allows a more rapid determination with a higher mass sensitivity ( $1 \mathrm{pg}$ for gold and silver NPs) and comparable size discrimination (0.27 $\mathrm{nm}$ ). The proposed EMSD-based method was capable of identifying trace $\mathrm{Ag}_{2} \mathrm{~S}$ NPs and core-shell nanocomposite $\mathrm{Au} @ \mathrm{Ag}$, as well as quantitatively tracking the dissolution and size transformation of silver nanoparticles in serum and environmental waters.
\end{abstract}

\section{INTRODUCTION}

Because of their excellent physicochemical properties, nanoparticles (NPs) have various applications in biomedicine, ${ }^{1}$ biotechnology, ${ }^{2}$ sensing, ${ }^{3}$ catalysis, ${ }^{4}$ and commercial products. ${ }^{5}$ However, there is growing concern that the increased use of NPs might lead to their continuous entry into the environment and food $w^{6} b^{6}$ and, therefore, growing public concerns about their impacts on human health and environmental safety. ${ }^{7-9}$ Even though many studies have demonstrated the toxicity of NPs to a variety of organisms, ${ }^{10,11}$ a detailed toxicity mechanism of NPs has not yet been fully elucidated. This can be partly attributed to the fact that, in addition to the composition, both the particle size and mass impact the toxicity of NPs. ${ }^{12,13}$ Hence, methods for mass quantification and size characterization of NPs in various matrixes are required.

Although many methods have been developed for the analysis of NPs, particle size and mass are commonly determined with different techniques. ${ }^{14-20}$ For the size characterization of NPs, microscopy- and spectroscopy-based techniques, such as transmission electron microscopy (TEM), scanning electron microscopy (SEM), and dynamic light scattering (DLS), are typically employed. However, these techniques suffer from low resolution or a lack of accuracy, and they are typically restricted in some situations. ${ }^{21}$ Mass quantification is generally based on size separation techniques including filtration, ${ }^{22}$ ultracentrifugation, ${ }^{10}$ and extraction-based methods, ${ }^{23-27}$ followed by determination with element-specific detectors such as inductively coupled plasma mass spectrometry (ICP-MS). Unfortunately, they are unable to separate NPs with different sizes.

Methods that simultaneously measure both particle size distribution and mass are sparse. Single-particle inductively coupled plasma mass spectrometry (spICP-MS) can determine these two parameters, but it has relatively high size detection limits (10-40 nm for most elements $)^{17,18,20}$ that are larger than most NPs of interest (less than 20-30 nm). ${ }^{9,19}$ Another potential approach is the coupling of size separation techniques, such as capillary electrophoresis (CE) ${ }^{28-30}$ hydrodynamic chromatography (HDC), ${ }^{31-33}$ field-flow fractionation (FFF), ${ }^{34-36}$ and size-exclusion chromatography (SEC), ${ }^{37-42}$ with highly sensitive detection techniques such as ICP-MS. Although this approach has the potential for size characterization and speciation analysis of metal-containing NPs and

Received: November 3, 2016

Revised: February 20, 2017

Accepted: March 1, 2017

Published: March 1, 2017 
their ionic counterparts in certain cases, the size distribution obtained from peak broadening shows a certain deviation compared with reality. ${ }^{30,40}$ Moreover, this approach is hindered by technical obstacles, namely, the particle-size-dependent response intensity of ICP-MS. ${ }^{30,41}$

Among the separation techniques used in online coupled systems, SEC is preferred to FFF, HDC, and CE for size characterization, because it is directly based on size-driven separation. SEC offers high repeatability and displays a strong linear relationship between retention time and particle size, thus providing high precision in size measurement. ${ }^{43}$ Size and shape separation of NPs and quantum dots (QDs) has been successfully carried out using $\mathrm{C}_{8}$ or $\mathrm{C}_{18}$ columns, ${ }^{44-47}$ although the low resolution of this approach limits its applicability in polydisperse NP separation. ${ }^{47}$ Although degradation or irreversible adsorption are reported in SEC, these phenomena can be minimized through the addition of surfactants such as sodium dodecyl sulfate (SDS). ${ }^{38-40,43,48,49}$

The objective of this study was to develop a robust and sensitive method for the simultaneous characterization, quantification, and identification of trace NPs with sizes of $<50 \mathrm{~nm}$, which are regarded as playing a central role in a wide range of applications ${ }^{9}$ and showed unique properties that would require regulatory scrutiny. ${ }^{19}$ Toward this end, the elemental mass size distribution (EMSD), integrating the particle size distribution, mass quantification, and elemental composition, was determined using online coupling of SEC with ICP-MS (SEC-ICP-MS). The proposed method extends the family of NP characterization and quantification techniques to better monitor the size and composition transformation of NPs contributing to their fate and risk. Strengths include the relatively high recoveries compared to published hyphenated techniques, as well as the efforts to correct instrumental broadening of a specific coupled instrument system.

\section{EXPERIMENTAL SECTION}

Chemicals and Materials. Citrate-stabilized silver nanoparticles (AgNPs) with nominal sizes of 10, 20, 40, 60, and 100 $\mathrm{nm}$ were obtained from Sigma-Aldrich (St. Louis, MO). Two certified gold nanoparticle (AuNP) dispersions (RM 8011 and RM 8012) with nominal sizes of 10 and $30 \mathrm{~nm}$ were purchased from the National Institute of Standards and Technology (NIST, Gaithersburg, MD). Two additional AuNP dispersions with nominal sizes of 5 and $60 \mathrm{~nm}$ were obtained from Jieyi Biotechnology Co., Ltd. (Shanghai, China). FL-70, a mixture of nonionic and anionic surfactants, which contains sodium carbonate, tetrasodium ethylene diamine tetraacetate, polyethylene glycol, water and alcohols, $\mathrm{C}_{12-14}$-secdondary, ethoxylated, was obtained from Fisher Scientific (Fair Lawn, $\mathrm{NJ}$ ), while other reagents were obtained from Beijing Chemicals (Beijing, China). Ultrapure water (18.3 M $\Omega$ ) produced with a Milli-Q gradient system (Millipore, Billerica, MA) was used throughout the experiments.

Tetraoctylammonium bromide- (TOAB-) coated AgNPs (ca. $2.7 \mathrm{~nm}$ ), citrate-capped AgNPs (ca. $5 \mathrm{~nm}$ ), poly(vinylpyrrolidone)- (PVP-) capped AgNPs (ca. $30 \mathrm{~nm}$ ), and $\mathrm{Ag}_{2} \mathrm{~S}$ NPs (ca. $18 \mathrm{~nm}$ ) were prepared according to previous studies. ${ }^{50-56}$ Details are provided in the Supporting Information. Note that all of the sizes in this study refer to diameters. The content of dissolved ions in these NPs, analyzed by our previously reported liquid chromatography- (LC-) ICP-MS method, ${ }^{42}$ was less than $5 \%$.
Instrumentation. The SEC-ICP-MS system consisted of an Agilent 1200 series LC system (Agilent Technologies, Palo Alto, CA) and an ICP-MS instrument. An Agilent 7700cs ICPMS instrument was used throughout the experiments except for the analysis of $\mathrm{Ag}_{2} \mathrm{~S}$ NPs, for which an Agilent 8800 ICP-MS instrument was used for the simultaneous determination of ${ }^{107} \mathrm{Ag}^{+}$and ${ }^{48} \mathrm{SO}^{+}$. The coupling of the SEC and ICP-MS instrument was accomplished by directly connecting the LC column outlet to the nebulizer of the ICP-MS instrument through a commercial polytetrafluoroethylene (PTFE) connector, the details of which were reported in our previous study. ${ }^{42}$ Two Venusil Durashell- $\mathrm{NH}_{2}$ columns $(250 \times 4.6 \mathrm{~mm})$ with pore sizes of $500 \AA$ (for $\leq 10-\mathrm{nm}$ NPs) and $1000 \AA$ (for $10-40-n m$ NPs) were used based on our previous study. ${ }^{42}$ The typical experimental parameters are summarized in Table S1.

EMSD Determination. Experiments were carried out by diluting a metal-containing NP sample in the mobile phase to a final concentration between 1 and $200 \mu \mathrm{g} / \mathrm{L}$ in terms of the metal. Each standard and sample solution was independently injected into the SEC-ICP-MS system. The EMSD was obtained by converting the retention time $\left(t_{\mathrm{r}}\right)$ of the SEC chromatogram into a diameter $(d)$ and then correcting for the instrumental broadening of the SEC-ICP-MS peak (Scheme 1).

Scheme 1. EMSD Determination for the Simultaneous Characterization, Quantification, and Identification of NPs by SEC-ICP-MS

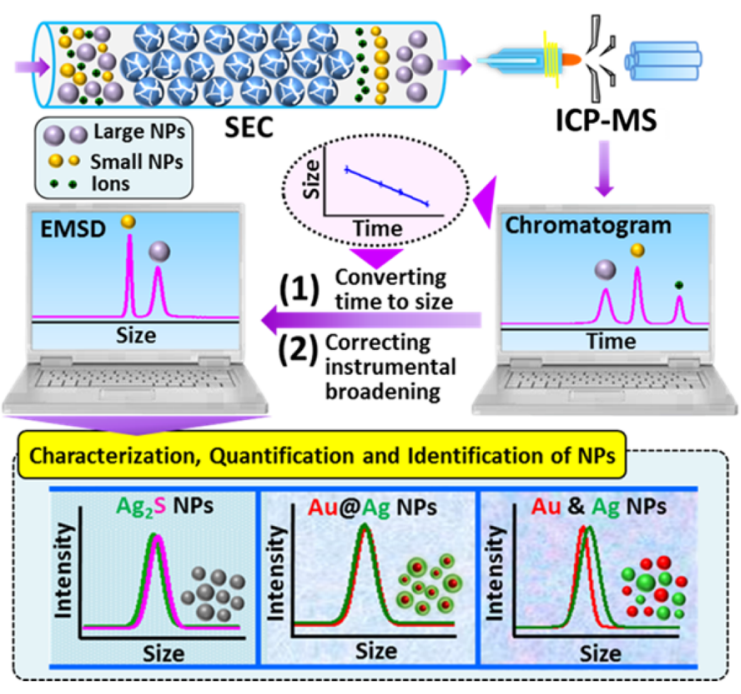

Correction of Instrumental Broadening. To obtain a more accurate size distribution, the instrumental broadening was corrected using a procedure modified from that of Colvin and co-workers, ${ }^{40}$ in which a monodisperse polystyrene sample was used as the standard to correct for the instrumental broadening of CdSe QDs in SEC. The dispersity $(\sigma / d)$ in diameter from TEM measurements agreed well with that obtained by SEC. Briefly, the correction was performed as follows (Figure 1): (i) Based on the $d-t_{\mathrm{r}}$ equation, the retention time of the SEC-ICP-MS chromatogram was converted into an NP diameter (Figure 1A). (ii) A Gaussian fit of the SEC-ICP-MS chromatogram was performed using OriginPro 8.5 software (OriginLab Corporation, Northampton, $\mathrm{MA})$, to obtain the mean diameter $(\bar{d})$ and variance $\left(\sigma_{0}\right)$ of the SEC-ICP-MS chromatogram (Figure 1B). The sample variance 


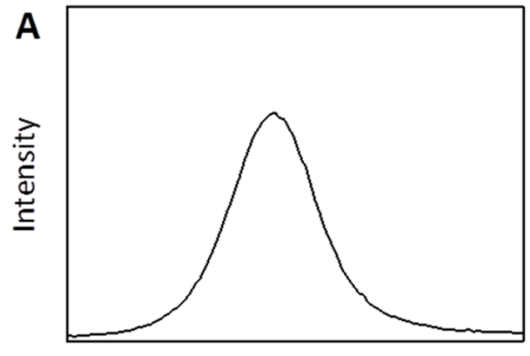

Diameter

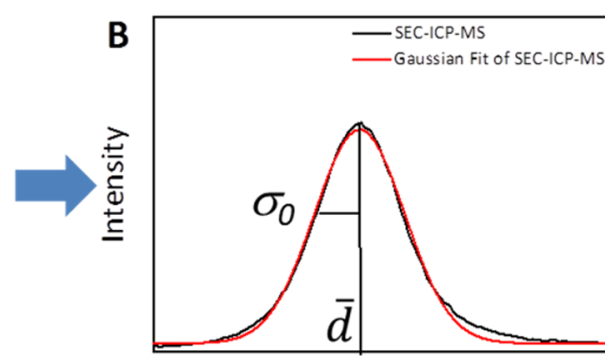

Diameter

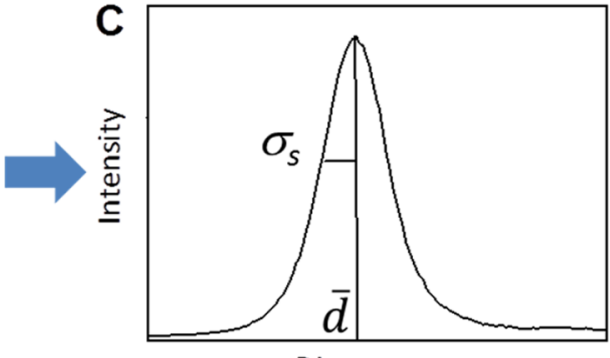

Diameter

Figure 1. Correction of the size distribution resulting from the instrumental broadening of the SEC-ICP-MS chromatogram. The correction procedure was performed as follows: (A) The retention time of the SEC-ICP-MS chromatogram was converted into NP diameter based on the $d-t_{\mathrm{r}}$ equations. (B) Gaussian fitting of the SEC-ICP-MS chromatogram was performed using OriginPro 8.5 software, from which the mean diameter $(\bar{d})$ and variance of the SEC-ICP-MS chromatogram $\left(\sigma_{0}\right)$ were obtained. (C) The particle diameter $\left(d_{\mathrm{s}}\right)$ was corrected based on the equation $d_{\mathrm{s}}=d_{0}-$ $\left[\left(d_{0}-\bar{d}\right) / \sigma_{0} \times\left(\sigma_{0}-\sigma_{\mathrm{s}}\right)\right]$, where $d_{0}$ is the uncorrected diameter shown in panel A and $d_{\mathrm{s}}$ is the corrected diameter shown in panel C, and the signal intensity was corrected by multiplying by $\sigma_{0} / \sigma_{\mathrm{s}}$. The peak obtained in panel C is the real size distribution of the NPs (EMSD), in which $\sigma_{\mathrm{s}}$ is the peak half-width at $0.607 \times$ peak height.

$\left(\sigma_{\mathrm{s}}\right)$ was calculated by subtracting the instrumental variance

$\left(\sigma_{\mathrm{I}}\right)$ from the total variance $\left(\sigma_{0}\right)$

$$
\sigma_{\mathrm{s}}^{2}=\sigma_{0}^{2}-\sigma_{\mathrm{I}}^{2}
$$

(iii) The particle diameter $\left(d_{\mathrm{s}}\right)$ was corrected using the equation

$$
d_{\mathrm{s}}=d_{0}-\left[\frac{d_{0}-\bar{d}}{\sigma_{0}} \times\left(\sigma_{0}-\sigma_{\mathrm{s}}\right)\right]
$$

where $d_{0}$ is the uncorrected diameter shown in Figure $1 \mathrm{~A}, d_{s}$ is the corrected diameter shown in Figure $1 \mathrm{C}$, and the signal intensity was corrected by multiplication by the factor $\sigma_{0} / \sigma_{\mathrm{s}}$. The peak obtained in Figure 1C (EMSD) is the real size distribution of the NPs, in which $\sigma_{\mathrm{s}}$ is the peak half-width at $0.607 \times$ peak height. $\sigma_{\mathrm{I}}$ was determined by measuring NPs with a known size distribution by SEC-ICP-MS. Here, the NIST RM 8011 (nominally 10-nm AuNPs) reference material, with a size distribution of $8.8 \pm 0.6 \mathrm{~nm}\left(\sigma_{\mathrm{s}}=0.6 \mathrm{~nm}\right)$ according to NIST documentation, was used as a standard. Upon injection of a NIST RM 8011 sample into the SEC-ICP-MS system, $\sigma_{0}$ values of $1.5 \mathrm{~nm}$ for the 1000- $\AA$ column and $1.4 \mathrm{~nm}$ for the $500-\AA$ column were determined. $\sigma_{\mathrm{I}}$ was then calculated as $1.4 \mathrm{~nm}$ for the $1000-\AA$ column and $1.3 \mathrm{~nm}$ for the $500-\AA$ column using eq 1. It is worth noting that only the peak half-width was changed by the correction, rather than the peak area.

TEM Characterization. TEM analysis was conducted using a JEM-2100F microscope (JEOL, Tokyo, Japan) operated at $200 \mathrm{kV}$. TEM samples were prepared following the method described in an earlier publication. ${ }^{29}$ Specifically, $5 \mu \mathrm{L}$ aliquots of NP sample solution were loaded onto a carbon-coated TEM grid $(\mathrm{Cu}, 200$ meshes, Zhongxingbairui Technology Co. Ltd., Beijing, China) and dried at room temperature under a vacuum. The particle number size distribution was determined by counting at least 200 particles with Nano Measurer 1.2 software. The sample was stained with $1 \%$ uranyl acetate for TEM observation of the protein corona. Briefly, AgNP samples were centrifuged once at $9000 \mathrm{rpm}$ for $30 \mathrm{~min}$ to remove most of the excess fetal bovine serum, and $5 \mu \mathrm{L}$ aliquots of the NP sample suspension were placed onto a carbon-coated copper grid and allowed to rest for $2 \mathrm{~min}$. The excess liquid was removed using filter paper, and the sample was stained with $1 \%$ $(\mathrm{m} / \mathrm{m})$ uranyl acetate for $4 \mathrm{~min}$. The excess liquid was removed with filter paper, and the sample was then dried at room temperature under a vacuum.
DLS Characterization. The hydrodynamic diameters of the NPs were determined by dynamic light scattering (DLS) on a Malvern Nano ZS instrument (Malvern Instruments Ltd., Malvern, U.K.) using $2 \mathrm{~mL}$ of a $1 \mathrm{mg} / \mathrm{L}$ NP suspension diluted with ultrapure water in a standard macro-cuvette (pass length = $1 \mathrm{~cm}$ ). The scattering angle was $173^{\circ}$, and the temperature was maintained at $25{ }^{\circ} \mathrm{C}$. The refractive index (RI) was 1.07, and the adsorption value was 0.01 for $\mathrm{NPs}^{57}$ Each DLS measurement was performed for 30 acquisitions, and for each sample, the DLS characterization was repeated three times.

Water Sample Collection. Three environmental water samples were collected to study the feasibility of the method for the quantification and size characterization of NPs in real water samples. Lake water was collected from a lake located at Peking University (Beijing, China). Municipal sewage influent and effluent were obtained from Qinghe wastewater treatment plant (WWTP) in northwest Beijing (China). All samples were collected in glass bottles, which were rinsed three times with the sample in advance and stored at $4{ }^{\circ} \mathrm{C}$. Real samples were filtered through $0.45-\mu \mathrm{m}$ membrane syringe filter [poly(ether sulfone) (PES)] to eliminate suspended solids. The $\mathrm{pH}$ and the concentrations of cations and dissolved organic matter (DOM) were determined before each experiment. All $\mathrm{pH}$ measurements were performed on an Orion $\mathrm{pH} / \mathrm{ISE}$ meter (model 710A, Thermo Fisher Scientific, Waltham, MA). Cations were determined with an Agilent 7700cs ICP-MS instrument. DOM was determined with a Phoenix 8000 UV-persulfate total organic carbon analyzer (Tekmar-Dohrmann,Cincinnati, $\mathrm{OH})$.

\section{RESULTS AND DISCUSSION}

Determination of EMSD. SEC Separation of NPS. In our previous study, ${ }^{42}$ we found that FL-70 and $\mathrm{Na}_{2} \mathrm{~S}_{2} \mathrm{O}_{3}$ play important roles in the elution of AgNPs and $\mathrm{Ag}^{+}$, respectively, from the column and that the column pore size is the key determining factor for the complete separation of $\mathrm{Ag}^{+}$and AgNPs in the range of $1-100 \mathrm{~nm}$. Although the baseline separation of $\mathrm{Ag}^{+}$and AgNPs was successfully achieved, polydisperse NPs were eluted in one fraction. Additionally, the selection of the SEC column is vital to the separation and characterizion of NPs, as was reviewed by Pitkänen and Striegel. ${ }^{47}$ Therefore, the separation behavior of polydisperse NPs was investigated in detail using different concentrations of FL-70 and $\mathrm{Na}_{2} \mathrm{~S}_{2} \mathrm{O}_{3}$, as well as columns with different pore 

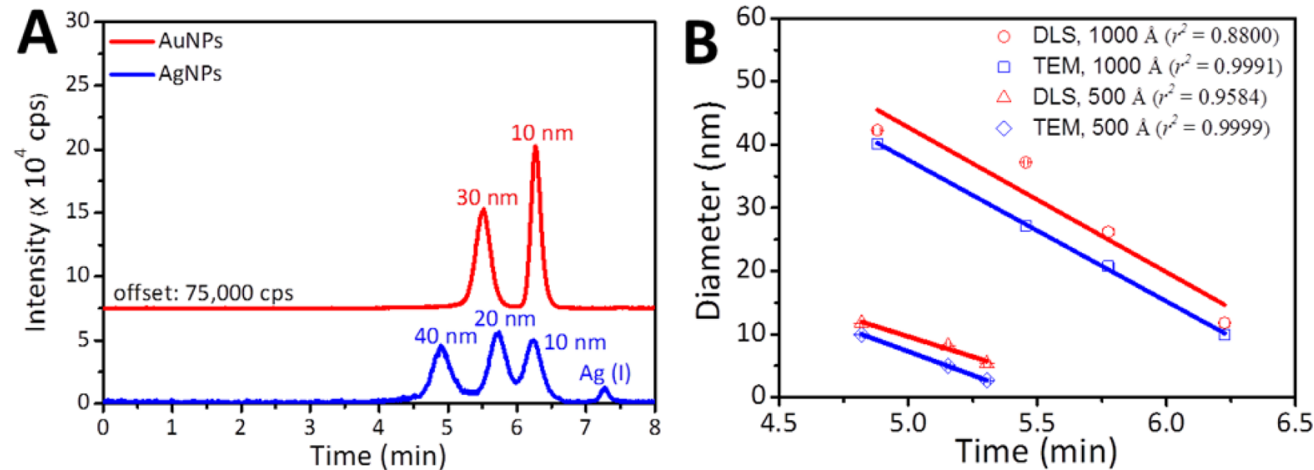

Figure 2. SEC separation of NPs. (A) Chromatograms of a mixture of AuNPs (10 and $30 \mathrm{~nm}$ ) and AgNPs (10, 20, and 40 nm) recorded by multielemental detection using SEC-ICP-MS with a 1000- $\AA$ amino column and an aqueous mobile phase of $2 \%(\mathrm{v} / \mathrm{v}) \mathrm{FL}-70$ and $2 \mathrm{mM} \mathrm{Na} \mathrm{S}_{2} \mathrm{O}_{3}$. (B) Linear correlation equation of particle diameter $(d)$ measured by TEM and DLS with the SEC-ICP-MS retention time $\left(t_{\mathrm{r}}\right)$ of the three AgNPs $(10,20$, and $40 \mathrm{~nm})$ and 30-nm AuNPs separated with a 1000- $\AA$ column, as well as 2.7-, 5.0-, and 10-nm AgNPs separated with a 500- $\AA$ column. Note: $x$-axis error bars show the standard deviations of the retention time from three consecutive SEC-ICP-MS measurements.

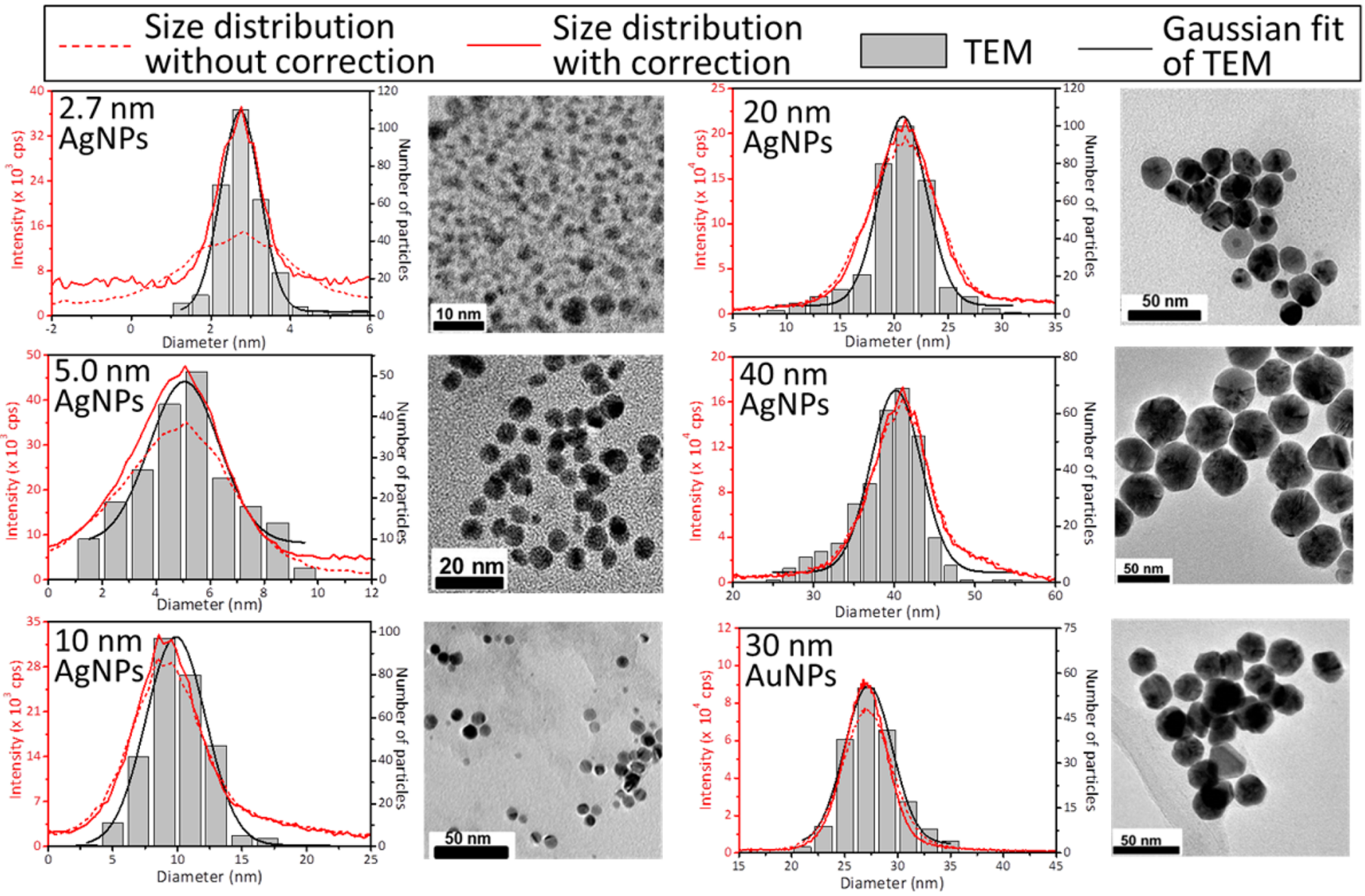

Figure 3. Size distribution profiles and TEM images of AuNP and AgNP standards. The red profiles were obtained by converting the time of the SEC-ICP-MS chromatogram to diameter without (short dashed line) and with (solid line) a correction for instrumental broadening. The black profile represents the particle number size distribution obtained from a Gaussian fit of the TEM histogram. Note that the particle size distribution profiles of the 10-nm AgNPs were obtained from the SEC-ICP-MS chromatogram determined with a 500-Å column, which was the same as that obtained with a $1000-\AA$ column.

sizes. Use of a 1000-Å-pore-size amino column and an aqueous mobile phase of $2 \%(\mathrm{v} / \mathrm{v})$ FL-70 and $2 \mathrm{mM} \mathrm{Na}_{2} \mathrm{~S}_{2} \mathrm{O}_{3}$ resulted in the satisfactory separation of AgNPs of three different sizes $(10,20$, and $40 \mathrm{~nm})$ and $\mathrm{Ag}(\mathrm{I})$ from each other with a separation resolution of $R>0.90$ (Figure S1). Note that 10and 20-nm AgNPs were not baseline separated because of their continuous particle size distribution.
Representative chromatograms of three sizes of citratestabilized AgNPs (10, 20, and $40 \mathrm{~nm})$ and two sizes of citratestabilized AuNPs (10 and $30 \mathrm{~nm}$ ) are shown in Figure 2A. The retention time was observed to increase with decreasing size, indicating that size-exclusion separation had occurred. To further confirm that the size-exclusion mechanism was operative, the retention time $\left(t_{\mathrm{r}}\right)$ in SEC-ICP-MS was analyzed as a function of the particle diameters $(d)$ measured by TEM 
and DLS. As shown in Figure 2B, $t_{\mathrm{r}}$ was more linearly correlated with $d$ values obtained by TEM $\left(r^{2}=0.9991\right.$ for the $1000-\AA$ column and $r^{2}=0.9999$ for the $500-\AA$ column) than by DLS $\left(r^{2}=0.8800\right.$ for the $1000-\AA$ column and $r^{2}=0.9584$ for the 500- $\AA$ column). These results can be attributed to the inaccuracy of DLS, as well as the inorganic salts in the mobile phase, which act to compress the hydration layer of the NPs in aqueous solution. Thus, the apparent size of the NPs by SEC was close to that obtained by TEM. $^{58}$ These results also qualitatively confirmed that the separation was based only on size-exclusion mechanisms. Although the $d-t_{\mathrm{r}}$ equation was valid for calibrating NP sizes in the range of $10-40 \mathrm{~nm}$, it failed in the evaluation of the $d$ values of small NPs with sizes of $<10$ $\mathrm{nm}$ because of their low resolution. A column with a smaller pore size $(500 \AA)$ in conjunction with $2.7-, 5.0$-, and 10-nm AgNPs as standards (see the chromatograms in Figure S2), however, resulted in a strong correlation equation $\left(d=-15.0 t_{\mathrm{r}}\right.$ $\left.+82.4, r^{2}=0.9999\right)$ for small NPs $(<10 \mathrm{~nm})$.

Size Characterization for EMSD Determination. The above-established $d-t_{\mathrm{r}}$ equations allowed for the generation of the size distribution profiles of the NPs by converting the $t_{\mathrm{r}}$ values of the SEC chromatograms into $d$ values. Because of the instrumental broadening in SEC-ICP-MS, however, the variance in the SEC-ICP-MS measurements $\left(\sigma_{0}\right)$ showed a slight deviation from the sample variance obtained by TEM, particularly for NPs with small $\sigma_{\mathrm{s}}$ values such as 2.7-nm TOABcapped AgNPs (Figure 3). To approach the actual size distribution as closely as possible, the instrumental variance $\left(\sigma_{\mathrm{I}}\right)$ in SEC-ICP-MS must be subtracted from $\sigma_{0}$. After this correction, the size distribution profiles of the 2.7-nm TOABcapped AgNPs, four sizes of citrate-coated AgNPs (5, 10, 20, and $40 \mathrm{~nm}$ ), and a citrate-coated AuNP standard from NIST with a certified size distribution of $26.7 \pm 1.5 \mathrm{~nm}$ were found to agree closely with the values obtained by Gaussian fits of the corresponding TEM histograms (Figure 3).

The calibrated system was further tested with 5-nm citratecoated AuNPs and 30-nm PVP-coated AgNPs. Analysis by EMSD determination resulted in size distributions of $5.0 \pm 1.2$ $\mathrm{nm}$ for the citrate-coated AuNPs and $28.6 \pm 5.1 \mathrm{~nm}$ for the PVP-coated AgNPs. These values are in good agreement with the size distributions of $4.9 \pm 1.3 \mathrm{~nm}$ for the AuNPs and $29.9 \pm$ $4.8 \mathrm{~nm}$ for the AgNPs, suggesting that the effects of the particle core species and coatings on EMSD determination were negligible. Thus, these results show that EMSD determination can provide high accuracy and precision in size characterization. It is noteworthy, however, that other factors in addition to instrumental broadening could contribute to deviations in the particle size distribution based on peak broadening in SEC. For example, van der Waals interactions represent a common shortcoming in SEC separations and lead to diffusion inside the column. ${ }^{39,48,49}$ Future work is needed to study the effects of diffusion on the size distribution in a quantitative fashion.

Mass Quantification for EMSD Determination. Quantifying the elemental mass distribution in polydiserse NPs represents another significant challenge in the determination of EMSDs. Prior studies reported that the size-dependent ICP-MS intensity in online coupling systems ${ }^{29,30,36,41,42}$ prohibit the quantification of polydisperse NPs with conventional ICP-MS element standards by external calibration. To overcome this limitation, we first identified the cause of the size-dependent ICP-MS intensity by determining the ICP-MS sensitivities (slope of a plot of ICP-MS intensity against concentration) of different-sized NPs (5-, 10-, 30-, 40-, and 60-nm AuNPs and
10-, 20-, 40-, 60-, and 100-nm AgNPs) and their ionic counterparts in the concentration range of $10-200 \mu \mathrm{g} / \mathrm{L}$ without SEC separation. The ICP-MS sensitivities of all NPs were in close agreement with those of their ionic counterparts (Figure S3), suggesting that the size-dependent response stemmed from the size-dependent mass recovery of the NPs from the column, instead of the size-dependent vaporization and diffusion in ICP-MS detection, as proposed in previous studies. ${ }^{30,41}$ Therefore, we attempted to enhance the elution of large NPs from the column by increasing the ionic strength of the mobile phase. The results showed that the addition of $\mathrm{NaNO}_{3}$ to the mobile phase considerably increased the ICPMS intensity, particularly for the 30- and 40-nm NPs (Figure S4). These results suggest that inorganic salts act to increase the elution of NPs from the column. The reason for this behavior is that inorganic salts decrease the apparent size of NPs in SEC, consistent with the increasing retention time observed with a rise in $\mathrm{NaNO}_{3}$ concentration (Figure S5).

Upon use of a mobile phase with a relatively high ionic strength (mixture of $2 \%$ FL-70 and $2 \mathrm{mM} \mathrm{Na}_{2} \mathrm{~S}_{2} \mathrm{O}_{3}$ ), all of the NPs $(\leq 40 \mathrm{~nm})$ exhibited sensitivities similar to those of their ionic counterparts (Figure 4). This allows for the use of the

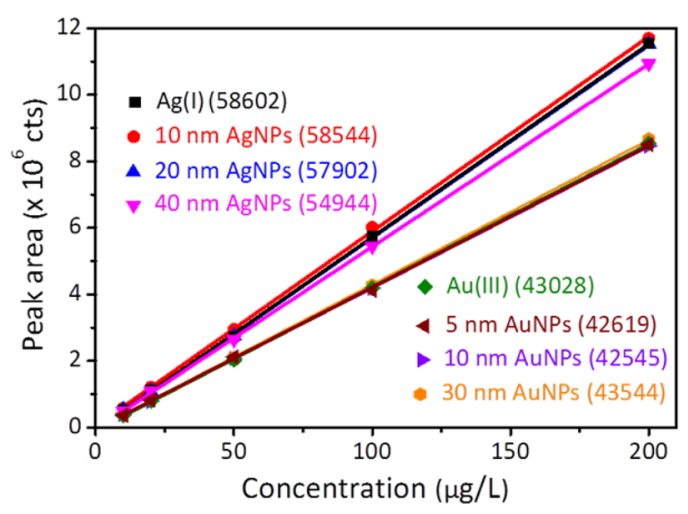

Figure 4. Linear plots of SEC-ICP-MS intensity against the concentrations of $\mathrm{Ag}(\mathrm{I}), \mathrm{Au}(\mathrm{III})$, and different-sized AgNPs (10, 20, and $40 \mathrm{~nm}$ ) and AuNPs $(5,10$, and $30 \mathrm{~nm})$. Note that the data in parentheses are the slopes of the corresponding species.

ICP-MS intensity to represent element mass in EMSD, as well as the respective quantification of NPs and their ionic counterparts in a single run. It is noted that the concentration of NPs within a certain size range can also be obtained from integral of the corresponding peak area, even for an incompletely separated peak. It should be highlighted that this is the first report of the quantification of polydisperse NPs by hyphenated techniques.

Analytical Performance. Different-sized NPs (10-, 20-, 40nm AgNPs and 5-, 10-, and 30-nm AuNPs) and their ionic counterparts were used for evaluation of the method. Parameters describing the analytical performance, including linear range, correlation coefficient $\left(r^{2}\right)$, limit of detection (LOD), relative standard deviation (RSD), and mass recovery, are reported in Table S2. Calibration curves for different concentrations of analytes were obtained with a high degree of linearity $\left(r^{2} \geq 0.9998\right)$. Analysis of ion and NP standard solutions containing $50 \mu \mathrm{g} / \mathrm{L} \mathrm{Ag}$ or $\mathrm{Au}$ for six measurements gave RSDs of $0.1-0.6 \%$ for retention time and $0.3-2.2 \%$ for peak area, which indicated high precision. The proposed method can readily distinguish between two samples differing 

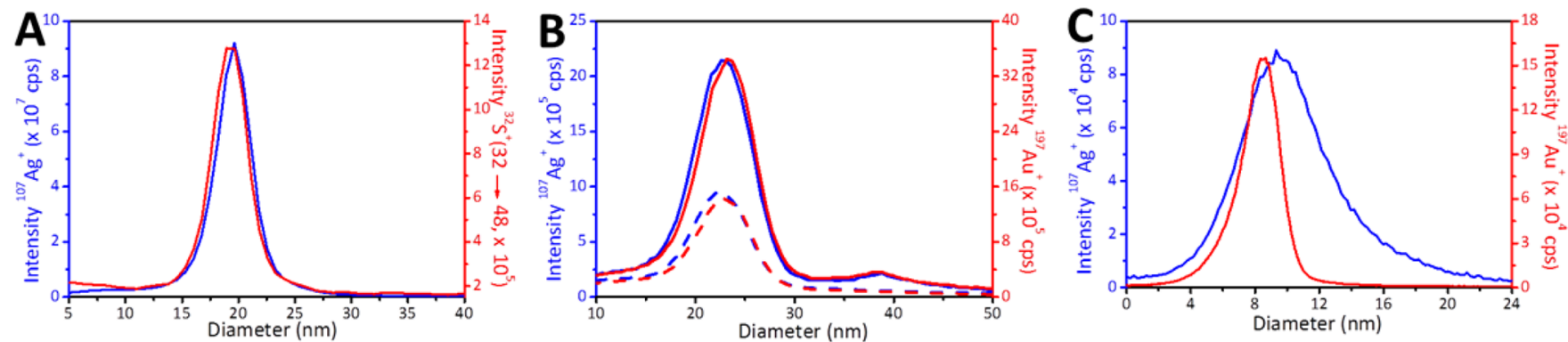

Figure 5. Composition identification of NPs by EMSD determination. (A) ${ }^{107} \mathrm{Ag}$ distribution and ${ }^{32} \mathrm{~S}$ distribution of $\mathrm{Ag}_{2} \mathrm{~S}$ determined simultaneously in a single run of SEC-ICP-MS. Note that the $2 \mathrm{mM} \mathrm{Na}_{2} \mathrm{~S}_{2} \mathrm{O}_{3}$ in the mobile phase was replaced with $5 \mathrm{mM} \mathrm{NaNO}{ }_{3}$ to avoid its interference in ${ }^{32} \mathrm{~S}$ SEC-ICP-MS determination. (B) ${ }^{107} \mathrm{Ag}$ distribution and ${ }^{197} \mathrm{Au}$ distribution of $\sim 23-\mathrm{nm} \mathrm{Au@Ag} \mathrm{core/shell} \mathrm{NPs} \mathrm{in} \mathrm{surface} \mathrm{water,} \mathrm{determined}$ simultaneously in a single SEC-ICP-MS run at spiked levels of $50 \mu \mathrm{g} / \mathrm{L}$ (dashed line) and $150 \mu \mathrm{g} / \mathrm{L}$ (solid line). Note that the bimodal distribution was not detected at the spiked level of $50 \mu \mathrm{g} / \mathrm{L}$, where the concentration of $\sim 39-\mathrm{nm} \mathrm{Au@Ag} \mathrm{core/shell} \mathrm{NPs} \mathrm{was} \mathrm{below} \mathrm{the} \mathrm{method} \mathrm{detection} \mathrm{limit.}$ (C) ${ }^{107} \mathrm{Ag}$ distribution and ${ }^{197} \mathrm{Au}$ distribution of a mixture of $10-\mathrm{nm}$ AgNPs $(20 \mu \mathrm{g} / \mathrm{L})$ and $10-\mathrm{nm}$ AuNPs $(20 \mu \mathrm{g} / \mathrm{L})$ determined simultaneously in a single SEC-ICP-MS run.
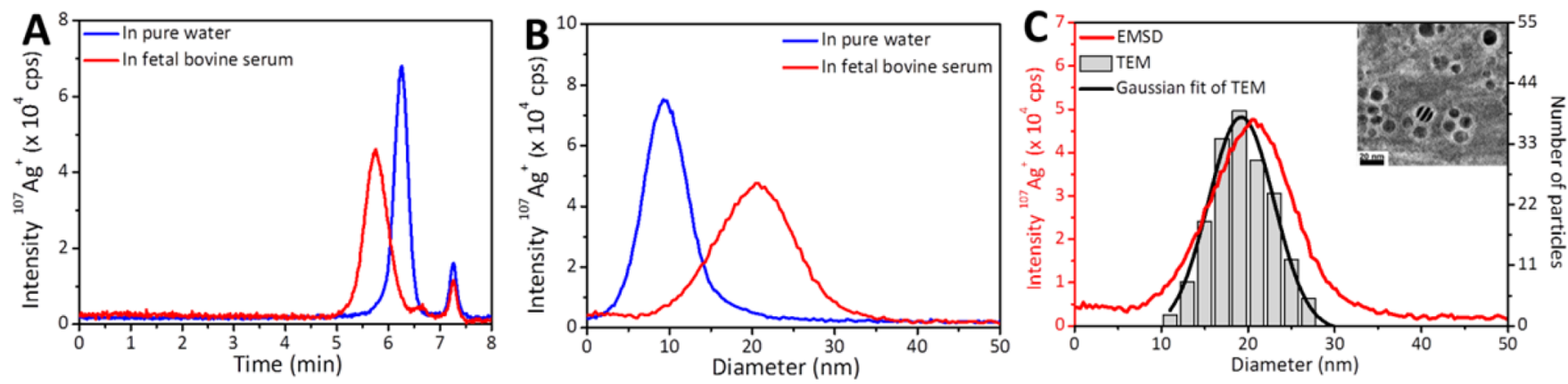

Figure 6. Transformation of AgNPs in fetal bovine serum. (A) SEC-ICP-MS chromatograms of $20 \mu \mathrm{g} / \mathrm{L}$ AgNPs in water and fetal bovine serum. Fetal bovine serum (5-fold diluted) was spiked with $1 \mathrm{mg} / \mathrm{L} \mathrm{AgNPs}$ and incubated for $1 \mathrm{~h}$, and then the mixture was diluted with the mobile phase [a mixture of $2 \%(\mathrm{v} / \mathrm{v})$ FL-70 and $2 \mathrm{mM} \mathrm{Na}_{2} \mathrm{~S}_{2} \mathrm{O}_{3}$ ] to $20 \mu \mathrm{g} / \mathrm{L}$ AgNPs before SEC-ICP-MS determination. Note that the NP size will change obviously once added to FBS. (B) ${ }^{107} \mathrm{Ag}$ EMSDs of $20 \mu \mathrm{g} / \mathrm{L}$ AgNPs in water and fetal bovine serum converted from panel A. (C) Comparison of the EMSD profile determined by SEC-ICP-MS and that obtained from the Gaussian fit of the TEM histogram of the AgNPs after incubation in fetal bovine serum for $1 \mathrm{~h}$. Inset: TEM image of $1 \mathrm{mg} / \mathrm{L}$ AgNPs after incubation in fetal bovine serum for $1 \mathrm{~h}$. Note that the sample was stained with $1 \%(\mathrm{~m} / \mathrm{m}$ ) uranyl acetate for TEM observation, where the dark color represents the AgNPs and the white areas surrounding the AgNPs represent the protein corona.

in size by only $0.27 \mathrm{~nm}$ (the ratio between 3 times the standard deviation of $t_{\mathrm{r}}$ and the slope of the $t_{\mathrm{r}}$ equation). To further evaluate the precision of the proposed method for real environmental water samples, citrate-coated AgNPs with a nominal size of $10 \mathrm{~nm}$ were spiked into WWTP influent at a level of $10 \mu \mathrm{g} / \mathrm{L}$ and measured for 11 times. The precision were very was highly satisfactory with RSDs of $0.2 \%$ for retention time and $2.3 \%$ for peak area. The detection limits, calculated as 3 times the baseline noise $(S / N=3)$ were low, in the submicrogram-per-liter range $(0.04-0.12 \mu \mathrm{g} / \mathrm{L}$ for $\mathrm{Ag}$ and $0.09-0.24 \mu \mathrm{g} / \mathrm{L}$ for $\mathrm{Au}$, corresponding to $1 \mathrm{pg}$ in a $20 \mu \mathrm{L}$ sample, depending on the $\sigma_{\mathrm{s}}$ value of the particle size distribution). In comparison to existing methods, the detection limits are 2-3 orders of magnitude lower than those obtained by FFF $\left(1.7-3.2 \mu \mathrm{g} / \mathrm{L}\right.$ for AgNPs) ${ }^{36}$ and less than half of those obtained by CE $(0.21-0.65 \mu \mathrm{g} / \mathrm{L}$ for AgNPs and $0.18-0.55$ $\mu \mathrm{g} / \mathrm{L}$ for AuNPs $)^{29,30}$ and LC $(0.08-0.40 \mu \mathrm{g} / \mathrm{L}$ for AgNPs $){ }^{41}$ Mass recoveries, evaluated as the ratios of the ICP-MS intensities obtained by injecting the same amount of analytes with SEC separation to those without SEC separation, were $>91 \%$, ensuring simultaneous quantification of polydisperse NPs with conventional elemental standards of ICP-MS by external calibration.

Comparison with Other Methods. Although many methods have been reported for the analysis of
NPs, ${ }^{26,30,36,41,42}$ they are not suitable for the mass quantification of different-sized NPs. This proposed method is valid not only in the size separation of NPs, but also in providing size distribution information and quantifying the masses of different-sized NPs in a single run. For size characterization, DLS and TEM are usually used to probe the size distributions of NPs at relatively high concentrations $(\mathrm{mg} / \mathrm{L})$ in simple matrixes, and sample preparation for TEM is time-consuming and can possibly give rise to imaging artifacts. Unlike DLS and TEM, the developed EMSD determination method exhibited higher sensitivity in size characterization $(\mu \mathrm{g} / \mathrm{L})$ and comparable size discrimination $(0.27 \mathrm{~nm})$ in complex matrixes, and it is low-cost, simple, straightforward, and rapid (8 min).

Applications of EMSD. Composition Identification of NPs. Direct identification of NPs at low concentration is a challenge even for modern techniques. In the next step of this work, the applicability of using EMSD for identification of trace $\mathrm{NPs}$ was evaluated (Figure 5) using $\mathrm{Ag}_{2} \mathrm{~S}$ NPs, which are the main transformation product of AgNPs in wastewater treatment plants, as model NPs, by determining ${ }^{107} \mathrm{Ag}^{+}$and ${ }^{48} \mathrm{SO}^{+}$ simultaneously in a single run. The overlap of the EMSD profiles of $\mathrm{Ag}$ and $\mathrm{S}$ indicated that the NPs contained both $\mathrm{Ag}$ and $\mathrm{S}$, and the molar ratio of $\mathrm{Ag}$ to $\mathrm{S}$ of 1:0.48 [calculated from the external calibration of $\mathrm{Ag}(\mathrm{I})$ and $\mathrm{S}^{2-}$ ] suggested a composition of $\mathrm{Ag}_{2} \mathrm{~S}$ (Figure 5A). EMSD determination was 
used to further distinguish nanocomposites ( 23-nm Au@Ag core/shell NPs, spiked at 50 or $150 \mu \mathrm{g} / \mathrm{L}$ in surface water) from a mixture of NPs $(\sim 10-\mathrm{nm}$ AuNPs and $\sim 10-\mathrm{nm}$ AgNPs, each spiked at $20 \mu \mathrm{g} / \mathrm{L}$ in surface water). Whereas the EMSD profiles of ${ }^{107} \mathrm{Ag}$ and ${ }^{197} \mathrm{Au}$ were in close agreement for the $\mathrm{Au} @ \mathrm{Ag}$ NPs, the same profiles were considerably different for the mixture of AuNPs and AgNPs, even though these NPs had the same particle size of $\sim 10 \mathrm{~nm}$ (Figure 5B,C). From the EMSDs of ${ }^{197} \mathrm{Au}$ and ${ }^{107} \mathrm{Ag}$, the exact $\mathrm{Au} / \mathrm{Ag}$ ratio of the $\mathrm{Au} @$ Ag NPs was calculated to be 2.34 according to the external calibration of $\mathrm{Ag}(\mathrm{I})$ and $\mathrm{Au}(\mathrm{III})$. The close agreement of the particle size distributions (average size \pm sample variance) in EMSD with those from TEM analysis $(19.7 \pm 1.6 \mathrm{~nm}$ vs $19.1 \pm$ $1.7 \mathrm{~nm}$ for $\mathrm{Ag}_{2} \mathrm{~S}, 22.7 \pm 2.9 \mathrm{~nm}$ vs $23.3 \pm 3.5 \mathrm{~nm}$ for $\mathrm{Au} @ \mathrm{Ag}$ ) again demonstrated the utility of the EMSD determination for size characterization (Figure S6).

Tracking the Transformation of NPs in Serum. Following the EMSD determination, experiments were performed to determine whether the method can track the transformation of NPs in a biological matrix. The change in the ${ }^{107} \mathrm{Ag}$ EMSD of $20 \mu \mathrm{g} / \mathrm{L}$ AgNPs in biofluid was measured. After incubation in fetal bovine serum (FBS) for $1 \mathrm{~h}$, the amount of AgNPs (peak area) was found to remain constant (Figure 6A), whereas the AgNP size (average size \pm polydispersity) increased significantly from $9.7 \pm 2.6$ to $19.9 \pm 4.8 \mathrm{~nm}$ (Figure $6 \mathrm{~B}$ ). These results were in good agreement with the size distribution profiles obtained by a Gaussian fit of the TEM histogram of the AgNPs $(19.2 \pm 3.8 \mathrm{~nm}$, Figure 6C) and with previous results reported for similar systems. ${ }^{59}$ The increase in particle size was attributed to the formation of a nanoparticle-protein corona through the attachment of proteins onto the NP surface. ${ }^{57}$ This phenomenon was verified by TEM analysis after the sample had been stained with $1 \%$ uranyl acetate. These results also indicated that the apparent size in EMSD is the sum of the core diameter and two thicknesses of coatings. Although a similar size transformation was observed in undiluted FBS by the proposed method, it was hard to obtain a clear TEM image because there was too much protein in the sample. It is noted that, although the size characterization of the corona can be achieved by TEM, the sample preparation is tedious and timeconsuming. Thus, the proposed method is complementary to TEM for the measurement of NP coating thicknesses.

Tracking the Transformation of NPs in Environmental Waters. EMSD determination was also applied to sensitively probe the size and chemical species transformation of AgNPs spiked in various environmental waters, which showed weak alkalinity ( $\mathrm{pH} 8.32-8.55)$ and considerable concentrations of common cations $\left(2.15-75.8 \mathrm{mg} / \mathrm{L} \mathrm{Na}^{+}, \mathrm{Mg}^{2+}, \mathrm{K}^{+}\right.$, and $\mathrm{Ca}^{2+}$ ) and DOM (18.7-46.8 $\mathrm{mg}$ of C/L), as shown in Table S3. Considering the relatively complex matrixes in these real waters, the spiked level (20 $\mu \mathrm{g} / \mathrm{L}$ AgNPs) in this study was comparable to or even far less than those used in previous studies on the transformation of AgNPs in real waters (10$2000 \mu \mathrm{g} / \mathrm{L}$ AgNPs). ${ }^{29,60-62}$ Most notably, although the coupling of cloud-point extraction (CPE) with spICP-MS achieved the determination and size characterization of AgNPs in real waters at the low nanogram-per-liter level, ${ }^{63}$ that method is still not suitable for the analysis of NPs with sizes of $<10 \mathrm{~nm}$ because of the high size detection limit of spICP-MS. When the water samples were analyzed immediately after being spiked with AgNPs, the total mass recoveries were in the range of 88.9-97.9\% with no significant size change, indicating that the matrixes of environmental waters including DOM, inorganic cations, and small sediments $(<0.45 \mu \mathrm{m})$ have limited influence on EMSD measurements and that EMSD determination is still effective under real conditions. After NPs had been spiked into lake water and the influent and effluent of WWTP for $6 \mathrm{~h}$, both the average size and polydispersity increased considerably, and 71.7-95.2\% of the spiked AgNPs remained as AgNPs, whereas $3.2-10.2 \%$ transformed into $\mathrm{Ag}(\mathrm{I})$ (Table S4). However, the total $\mathrm{Ag}$ mass recoveries were in the range of $77.5-103.7 \%$, again demonstrating that EMSD determination is valid in real environmental water samples. It should be noted that, considering the relatively higher level of AgNPs in the spiked samples compared to real environments, the transformation of AgNPs in Table S4 could be somewhat different from that at low concentrations; thus, further research at environmental concentration levels is still needed. It is further noted that conventional characterization techniques such as TEM, atomic force microscopy (AFM), and DLS are typically unable to determine such small changes in NP size distributions at trace levels $(\mu \mathrm{g} / \mathrm{L})$.

To test whether the particulate matter in real water will clog the column and therefore affect the EMSD determination after long-term usage, a sample of $10-\mathrm{nm}$ AgNPs $(10 \mu \mathrm{g} / \mathrm{L})$ in WWTP influent was injected into the SEC-ICP-MS system before and after 100 consecutive injection of WWTP influent samples. The results showed that no obvious changes in retention time and peak area were observed for both AgNPs and $\mathrm{Ag}^{+}$in these two determinations (Figure S7) and that the column pressure remained constant ( $45 \mathrm{bar}$ ), indicating that the particulate matter $(<0.45 \mu \mathrm{m})$ has a negligible influence on EMSD determinations.

Although the filtration of real samples before EMSD determination can avoid the risks of clogging the SEC column and the cross-flow nebulizer of the ICP-MS instrument, it could cause systematic error from mass loss because of the adsorption of AgNPs and $\mathrm{Ag}^{+}$on the $>0.45-\mu$ m particles in real samples. ${ }^{64}$ Thus, the mass losses of AgNPs and $\mathrm{Ag}^{+}$from the filtration of real waters were evaluated using real water samples that were spiked with $0.5 \mu \mathrm{g} / \mathrm{L} \mathrm{AgNPs} \mathrm{or} \mathrm{Ag}^{+}$before filtration. The measured mass losses were 96.4-100\% for AgNPs and 6.4$11.1 \%$ for $\mathrm{Ag}^{+}$(Figure S8), indicating that almost all of the NPs were lost during filtration. The high mass loss of the AgNPs in ultrapure water $(>88.4 \%)$ further suggested that the mass loss was caused mainly by their irreversible adsorption onto the filter membrane, rather than onto suspended organic matter with sizes of $>0.45 \mu \mathrm{m}$, as reported previously. ${ }^{64}$ However, further experiments demonstrated that, upon addition of a mixture of surfactant (FL-70) and $\mathrm{Na}_{2} \mathrm{~S}_{2} \mathrm{O}_{3}$ to the sample prior to filtration, the recoveries of citrate-coated AgNPs, PVP-coated AgNPs, and $\mathrm{Ag}^{+}$in real waters at the spiking level of $0.5 \mu \mathrm{g} / \mathrm{L}$ $\mathrm{Ag}$ were $83.7-86.8 \%, 89.9-92.4 \%$, and $96.5-99.6 \%$, respectively (Figure S9). These results indicate that the filtration of real samples has a negligible effect on the determination of AgNPs and $\mathrm{Ag}^{+}$if a mixture of surfactant (FL-70) and $\mathrm{Na}_{2} \mathrm{~S}_{2} \mathrm{O}_{3}$ is added prior to filtration.

In summary, EMSD was proposed for the first time for the size characterization, mass quantification, and composition identification of trace NPs in complex environmental and biological matrixes. In comparison with existing methods, this method provides higher throughput and sensitivity in mass quantification ( $1 \mathrm{pg}$ for gold and silver NPs) and comparable size discrimination $(0.27 \mathrm{~nm})$. Complex biological and environmental samples, namely, AgNPs spiked into serum and environmental waters, were analyzed, and the proposed 
method was shown to provide accurate size distributions and satisfactory mass recoveries. This method provides a new route for investigating polydisperse NP systems. Experiments to extend this method to more complex matrixes such as cells and animal tissues are underway. However, it remains difficult to satisfy the requirements of NP determination $(1-50 \mathrm{~nm})$ at low nanogram-per-liter levels in real world samples. Further efforts are needed to improve the analytical performance of this method through coupling with other preconcentration methods [e.g., CPE and solid-phase extraction (SPE)]. Nevertheless, because of its significant advantages over existing methods, the proposed EMSD determination would serve as a promising analytical method for nanoparticle research.

\section{ASSOCIATED CONTENT}

\section{S Supporting Information}

The Supporting Information is available free of charge on the ACS Publications website at DOI: 10.1021/acs.est.6b05539.

Details about the synthesis of NPs and additional references (Figures S1-S9 and Tables S1-S4) (PDF)

\section{AUTHOR INFORMATION}

\section{Corresponding Author}

*Phone: +86-10-62849192; fax: +86-10-62849192; e-mail: jfliu@rcees.ac.cn.

\section{ORCID 1}

Jing-fu Liu: 0000-0001-7134-7026

Notes

The authors declare no competing financial interest.

\section{ACKNOWLEDGMENTS}

This work was supported by the National Natural Science Foundation of China (21337004), the National Key Research and Development Program of China (2016YFA0203102), the Strategic Priority Research Program of the Chinese Academy of Sciences (XDB14020101), and the National Natural Science Foundation of China (21620102008).

\section{REFERENCES}

(1) Chaloupka, K.; Malam, Y.; Seifalian, A. M. Nanosilver as a New Generation of Nanoproduct in Biomedical Applications. Trends Biotechnol. 2010, 28, 580-588.

(2) Yoo, J. W.; Irvine, D. J.; Discher, D. E.; Mitragotri, S. Bioinspired, Bioengineered and Biomimetic Drug Delivery Carriers. Nat. Rev. Drug Discovery 2011, 10, 521-535.

(3) Saha, K.; Agasti, S. S.; Kim, C.; Li, X.; Rotello, V. M. Gold Nanoparticles in Chemical and Biological Sensing. Chem. Rev. 2012, 112, 2739-2779.

(4) Han, Z.; Qiu, F.; Eisenberg, R.; Holland, P. L.; Krauss, T. D. Robust Photogeneration of $\mathrm{H}-2$ in Water Using Semiconductor Nanocrystals and a Nickel Catalyst. Science 2012, 338, 1321-1324.

(5) Nowack, B.; Krug, H.; Height, M. 120 Years of Nanosilver History: Implications for Policy Makers. Environ. Sci. Technol. 2011, 45, 3189-3189.

(6) Ferry, J. L.; Craig, P.; Hexel, C.; Sisco, P.; Frey, R.; Pennington, P. L.; Fulton, M. H.; Scott, I. G.; Decho, A. W.; Kashiwada, S.; Murphy, C. J.; Shaw, T. J. Transfer of Gold Nanoparticles from the Water Column to the Estuarine Food Web. Nat. Nanotechnol. 2009, 4, 441-444.

(7) Nel, A.; Xia, T.; Madler, L.; Li, N. Toxic Potential of Materials at the Nanolevel. Science 2006, 311, 622-627.

(8) Maynard, A. D.; Aitken, R. J.; Butz, T.; Colvin, V.; Donaldson, K.; Oberdoerster, G.; Philbert, M. A.; Ryan, J.; Seaton, A.; Stone, V.;
Tinkle, S. S.; Tran, L.; Walker, N. J.; Warheit, D. B. Safe Handling of Nanotechnology. Nature 2006, 444, 267-269.

(9) Auffan, M.; Rose, J.; Bottero, J.-Y.; Lowry, G. V.; Jolivet, J. P.; Wiesner, M. R. Towards a Definition of Inorganic Nanoparticles from an Environmental, Health and Safety Perspective. Nat. Nanotechnol. 2009, 4, 634-641.

(10) Navarro, E.; Piccapietra, F.; Wagner, B.; Marconi, F.; Kaegi, R.; Odzak, N.; Sigg, L.; Behra, R. Toxicity of Silver Nanoparticles to Chlamydomonas reinhardtii. Environ. Sci. Technol. 2008, 42, 89598964.

(11) AshaRani, P. V.; Low Kah Mun, G.; Hande, M. P.; Valiyaveettil, S. Cytotoxicity and Genotoxicity of Silver Nanoparticles in Human Cells. ACS Nano 2009, 3, 279-290.

(12) Wijnhoven, S. W. P.; Peijnenburg, W. J. G. M.; Herberts, C. A.; Hagens, W. I.; Oomen, A. G.; Heugens, E. H. W.; Roszek, B.; Bisschops, J.; Gosens, I.; Van de Meent, D.; Dekkers, S.; De Jong, W. H.; Van Zijverden, M.; Sips, A. J. A. M.; Geertsma, R. E. Nano-Silver a Review of Available Data and Knowledge Gaps in Human and Environmental Risk Assessment. Nanotoxicology 2009, 3, 109-138.

(13) Guo, X.; Li, Y.; Yan, J.; Ingle, T.; Jones, M. Y.; Mei, N.; Boudreau, M. D.; Cunningham, C. K.; Abbas, M.; Paredes, A. M.; Zhou, T.; Moore, M. M.; Howard, P. C.; Chen, T. Size- and CoatingDependent Cytotoxicity and Genotoxicity of Silver Nanoparticles Evaluated Using in Vitro Standard Assays. Nanotoxicology 2016, 10, 1373-1384.

(14) Domingos, R. F.; Baalousha, M. A.; Ju-Nam, Y.; Reid, M. M.; Tufenkji, N.; Lead, J. R.; Leppard, G. G.; Wilkinson, K. J. Characterizing Manufactured Nanoparticles in the Environment: Multimethod Determination of Particle Sizes. Environ. Sci. Technol. 2009, 43, 7277-7284.

(15) Fraikin, J. L.; Teesalu, T.; McKenney, C. M.; Ruoslahti, E.; Cleland, A. N. A High-throughput Label-free Nanoparticle Analyser. Nat. Nanotechnol. 2011, 6, 308-313.

(16) He, X.; Zhang, Z.; Liu, J.; Ma, Y.; Zhang, P.; Li, Y.; Wu, Z.; Zhao, Y.; Chai, Z. Quantifying the Biodistribution of Nanoparticles. Nat. Nanotechnol. 2011, 6, 755-755.

(17) Pace, H. E.; Rogers, N. J.; Jarolimek, C.; Coleman, V. A.; Higgins, C. P.; Ranville, J. F. Determining Transport Efficiency for the Purpose of Counting and Sizing Nanoparticles via Single Particle Inductively Coupled Plasma Mass Spectrometry. Anal. Chem. 2011, 83, 9361-9369.

(18) Laborda, F.; Jimenez-Lamana, J.; Bolea, E.; Castillo, J. R. Selective Identification, Characterization and Determination of Dissolved Silver(I) and Silver Nanoparticles Based on Single Particle Detection by Inductively Coupled Plasma Mass Spectrometry. J. Anal. At. Spectrom. 2011, 26, 1362-1371.

(19) Olcum, S.; Cermak, N.; Wasserman, S. C.; Christine, K. S.; Atsumi, H.; Payer, K. R.; Shen, W.; Lee, J.; Belcher, A. M.; Bhatia, S. N.; Manalis, S. R. Weighing Nanoparticles in Solution at the Attogram Scale. Proc. Natl. Acad. Sci. U. S. A. 2014, 111, 1310-1315.

(20) Lee, S.; Bi, X.; Reed, R. B.; Ranville, J. F.; Herckes, P.; Westerhoff, P. Nanoparticle Size Detection Limits by Single Particle ICP-MS for 40 Elements. Environ. Sci. Technol. 2014, 48, 1029110300.

(21) Pace, H. E.; Rogers, N. J.; Jarolimek, C.; Coleman, V. A.; Gray, E. P.; Higgins, C. P.; Ranville, J. F. Single Particle Inductively Coupled Plasma-Mass Spectrometry: A Performance Evaluation and Method Comparison in the Determination of Nanoparticle Size. Environ. Sci. Technol. 2012, 46, 12272-12280.

(22) Trefry, J. C.; Monahan, J. L.; Weaver, K. M.; Meyerhoefer, A. J.; Markopolous, M. M.; Arnold, Z. S.; Wooley, D. P.; Pavel, I. E. Size Selection and Concentration of Silver Nanoparticles by Tangential Flow Ultrafiltration for SERS-Based Biosensors. J. Am. Chem. Soc. 2010, 132, 10970-10972.

(23) Liu, J. F.; Chao, J. B.; Liu, R.; Tan, Z. Q.; Yin, Y. G.; Wu, Y.; Jiang, G. B. Cloud Point Extraction as an Advantageous Preconcentration Approach for Analysis of Trace Silver Nanoparticles in Environmental Waters. Anal. Chem. 2009, 81, 6496-6502. 
(24) Chao, J. B.; Liu, J. F.; Yu, S. J.; Feng, Y. D.; Tan, Z. Q.; Liu, R.; Yin, Y. G. Speciation Analysis of Silver Nanoparticles and Silver Ions in Antibacterial Products and Environmental Waters via Cloud Point Extraction-Based Separation. Anal. Chem. 2011, 83, 6875-6882.

(25) Li, L.; Leopold, K. Ligand-Assisted Extraction for Separation and Preconcentration of Gold Nanoparticles from Waters. Anal. Chem. 2012, 84, 4340-4349.

(26) Zhang, L.; Chen, B.; He, M.; Liu, X.; Hu, B. Hydrophilic Polymer Monolithic Capillary Microextraction Online Coupled to ICPMS for the Determination of Carboxyl Group-Containing Gold Nanoparticles in Environmental Waters. Anal. Chem. 2015, 87, 17891796.

(27) Zhou, X. X.; Liu, J. F.; Yuan, C. G.; Chen, Y. S. Speciation Analysis of Silver Sulfide Nanoparticles in Environmental Waters by Magnetic Solid-Phase Extraction Coupled with ICP-MS. J. Anal. At. Spectrom. 2016, 31, 2285-2292.

(28) von der Kammer, F.; Ferguson, P. L.; Holden, P. A.; Masion, A.; Rogers, K. R.; Klaine, S. J.; Koelmans, A. A.; Horne, N.; Unrine, J. M. Analysis of Engineered Nanomaterials in Complex Matrices (Environment and Biota): General Considerations and Conceptual Case Studies. Environ. Toxicol. Chem. 2012, 31, 32-49.

(29) Liu, L. H.; He, B.; Liu, Q.; Yun, Z. J.; Yan, X.; Long, Y.; Jiang, G. Identification and Accurate Size Characterization of Nanoparticles in Complex Media. Angew. Chem., Int. Ed. 2014, 53, 14476-14479.

(30) Franze, B.; Engelhard, C. Fast Separation, Characterization, and Speciation of Gold and Silver Nanoparticles and Their Ionic Counterparts with Micellar Electrokinetic Chromatography Coupled to ICP-MS. Anal. Chem. 2014, 86, 5713-5720.

(31) Pergantis, S. A.; Jones-Lepp, T. L.; Heithmar, E. M. Hydrodynamic Chromatography Online with Single Particle-Inductively Coupled Plasma Mass Spectrometry for Ultratrace Detection of Metal-Containing Nanoparticles. Anal. Chem. 2012, 84, 6454-6462.

(32) Rakcheev, D.; Philippe, A.; Schaumann, G. E. Hydrodynamic Chromatography Coupled with Single Particle-Inductively Coupled Plasma Mass Spectrometry for Investigating Nanoparticles Agglomerates. Anal. Chem. 2013, 85, 10643-10647.

(33) Lewis, D. J. Hydrodynamic Chromatography - Inductively Coupled Plasma Mass Spectrometry, with Post-Column Injection Capability for Simultaneous Determination of Nanoparticle Size, Mass Concentration and Particle Number Concentration (HDC-PCi-ICPMS). Analyst 2015, 140, 1624-1628.

(34) Baalousha, M.; Stolpe, B.; Lead, J. R. Flow Field-Flow Fractionation for the Analysis and Characterization of Natural Colloids and Manufactured Nanoparticles in Environmental Systems: A Critical Review. J. Chromatogr. A 2011, 1218, 4078-4103.

(35) Barahona, F.; Geiss, O.; Urban, P.; Ojea-Jimenez, I.; Gilliland, D.; Barrero-Moreno, J. Simultaneous Determination of Size and Quantification of Silica Nanoparticles by Asymmetric Flow Field-Flow Fractionation Coupled to ICPMS Using Silica Nanoparticles Standards. Anal. Chem. 2015, 87, 3039-3047.

(36) Tan, Z. Q.; Liu, J. F.; Guo, X. R.; Yin, Y. G.; Byeon, S. K.; Moon, M. H.; Jiang, G. B. Toward Full Spectrum Speciation of Silver Nanoparticles and Ionic Silver by On-Line Coupling of Hollow Fiber Flow Field-Flow Fractionation and Minicolumn Concentration with Multiple Detectors. Anal. Chem. 2015, 87, 8441-8447.

(37) Huve, P.; Verrecchia, T.; Bazile, D.; Vauthier, C.; Couvreur, P. Simultaneous Use of Size-Exclusion Chromatography and PhotoCorrelation Spectroscopy for the Characterization Poly(Lactic Acid) Nanoparticles. J. Chromatogr. A 1994, 675, 129-139.

(38) Fischer, C. H.; Siebrands, T. Analysis of Colloids. 8. Concentration and Memory Effects in Size-Exclusion Chromatography of Colloidal Inorganic Nanometer-Particles. J. Chromatogr. A 1995, 707, 189-197.

(39) Wei, G. T.; Liu, F. K. Separation of Nanometer Gold Particles by Size Exclusion Chromatography. J. Chromatogr. A 1999, 836, 253260.

(40) Krueger, K. M.; Al-Somali, A. M.; Falkner, J. C.; Colvin, V. L. Characterization of Nanocrystalline CdSe by Size Exclusion Chromatography. Anal. Chem. 2005, 77, 3511-3515.
(41) Soto-Alvaredo, J.; Montes-Bayon, M.; Bettmer, J. Speciation of Silver Nanoparticles and Silver(I) by Reversed-Phase Liquid Chromatography Coupled to ICPMS. Anal. Chem. 2013, 85, 13161321.

(42) Zhou, X. X.; Liu, R.; Liu, J. F. Rapid Chromatographic Separation of Dissoluble $\mathrm{Ag}(\mathrm{I})$ and Silver-Containing Nanoparticles of 1-100 Nanometer in Antibacterial Products and Environmental Waters. Environ. Sci. Technol. 2014, 48, 14516-14524.

(43) Al-Sid-Cheikh, M.; Pedrot, M.; Bouhnik-Le Coz, M.; Dia, A.; Davranche, M.; Neaime, C.; Grasset, F. Robust Method Using Online Steric Exclusion Chromatography-Ultraviolet-Inductively Coupled Plasma Mass Spectrometry To Investigate Nanoparticle Fate and Behavior in Environmental Samples. Anal. Chem. 2015, 87, 1034610353.

(44) Alamo-Nole, L.; Bailon-Ruiz, S.; Perales-Perez, O.; Roman, F. R. Preparative Size-Exclusion Chromatography for Separation and Purification of Water-Stable Cd-Based Quantum Dots. Anal. Methods 2012, 4, 3127-3132.

(45) Liu, F. K. Using Size-Exclusion Chromatography to Monitor the Stabilization of Au Nanoparticles in the Presence of Salt and Organic Solvent. Chromatographia 2012, 75, 1099-1105.

(46) Paydary, P.; Larese-Casanova, P. Separation and Quantification of Quantum Dots and Dissolved Metal Cations by Size Exclusion Chromatography-ICP-MS. Int. J. Environ. Anal. Chem. 2015, 95, $1450-1470$.

(47) Pitkänen, L.; Striegel, A. M. Size-Exclusion Chromatography of Metal Nanoparticles and Quantum Dots. TrAC, Trends Anal. Chem. 2016, 80, 311-320.

(48) Wei, G. T.; Liu, F. K.; Wang, C. R. C. Shape Separation of Nanometer Gold Particles by Size-Exclusion Chromotography. Anal. Chem. 1999, 71, 2085-2091.

(49) Zhou, X. X.; Liu, J. F.; Geng, F. L. Determination of Metal Oxide Nanoparticles and Their Ionic Counterparts in Environmental Waters by Size Exclusion Chromatography Coupled to ICP-MS. NanoImpact 2016, 1, 13-20.

(50) Brust, M.; Walker, M.; Bethell, D.; Schiffrin, D. J.; Whyman, R. Synthesis of Thiol-Derivatised Gold Nanoparticles in a Two-Phase Liquid-Liquid System. J. Chem. Soc., Chem. Commun. 1994, 801-802.

(51) Silvert, P. Y.; HerreraUrbina, R.; Duvauchelle, N.; Vijayakrishnan, V.; Elhsissen, K. T. Preparation of Colloidal Silver Dispersions by the Polyol Process. Part 1-Synthesis and Characterization. J. Mater. Chem. 1996, 6, 573-577.

(52) Jana, N. R.; Gearheart, L.; Murphy, C. J. Seeding Growth for Size Control of 5-40 nm Diameter Gold Nanoparticles. Langmuir 2001, 17, 6782-6786.

(53) Xue, C.; Mirkin, C. A. pH-Switchable Silver Nanoprism Growth Pathways. Angew. Chem., Int. Ed. 2007, 46, 2036-2038.

(54) Yang, J.; Ying, J. Y. Nanocomposites of $\mathrm{Ag}_{2} \mathrm{~S}$ and Noble Metals. Angew. Chem., Int. Ed. 2011, 50, 4637-4643.

(55) Gao, C.; Vuong, J.; Zhang, Q.; Liu, Y.; Yin, Y. One-Step Seeded Growth of $\mathrm{Au}$ Nanoparticles with Widely Tunable Sizes. Nanoscale 2012, 4, 2875-2878.

(56) Gao, C.; Hu, Y.; Wang, M.; Chi, M.; Yin, Y. Fully Alloyed Ag/ $\mathrm{Au}$ Nanospheres: Combining the Plasmonic Property of Ag with the Stability of Au. J. Am. Chem. Soc. 2014, 136, 7474-7479.

(57) Zhang, W.; Yao, Y.; Sullivan, N.; Chen, Y. Modeling the Primary Size Effects of Citrate-Coated Silver Nanoparticles on Their Ion Release Kinetics. Environ. Sci. Technol. 2011, 45, 4422-4428.

(58) Potschka, M. Size-Exclusion Chromatogram of Poly-Electrolytes-Experimental-Evidence for a General Mechanism. J. Chromatogr. 1988, 441, 239-260.

(59) Monopoli, M. P.; Walczyk, D.; Campbell, A.; Elia, G.; Lynch, I.; Baldelli Bombelli, F.; Dawson, K. A. Physical-Chemical Aspects of Protein Corona: Relevance to in Vitro and in Vivo Biological Impacts of Nanoparticles. J. Am. Chem. Soc. 2011, 133, 2525-2534.

(60) Yin, Y. G.; Shen, M. H.; Tan, Z. Q.; Yu, S. J.; Liu, J. F.; Jiang, G. B. Particle Coating-Dependent Interaction of Molecular Weight Fractionated Natural Organic Matter: Impacts on the Aggregation of Silver Nanoparticles. Environ. Sci. Technol. 2015, 49, 6581-6589. 
(61) Pettibone, J. M.; Liu, J. In Situ Methods for Monitoring Silver Nanoparticle Sulfidation in Simulated Waters. Environ. Sci. Technol. 2016, 50, 11145-11153.

(62) Azodi, M.; Sultan, Y.; Ghoshal, S. Dissolution Behavior of Silver Nanoparticles and Formation of Secondary Silver Nanoparticles in Municipal Wastewater by Single-Particle ICP-MS. Environ. Sci. Technol. 2016, 50, 13318-13327.

(63) Li, L.; Stoiber, M.; Wimmer, A.; Xu, Z.; Lindenblatt, C.; Helmreich, B.; Schuster, M. To What Extent Can Full-Scale Wastewater Treatment Plant Effluent Influence the Occurrence of Silver-Based Nanoparticles in Surface Waters? Environ. Sci. Technol. 2016, 50, 6327-6333.

(64) Li, L.; Hartmann, G.; Doeblinger, M.; Schuster, M. Quantification of Nanoscale Silver Particles Removal and Release from Municipal Wastewater Treatment Plants in Germany. Environ. Sci. Technol. 2013, 47, 7317-7323. 